\title{
Kidney-Lung Crosstalk in the Critically III Patient
}

\author{
Gang Jee Ko ${ }^{a}$ Hamid Rabb ${ }^{a}$ Heitham T. Hassoun ${ }^{b}$ \\ Departments of a Medicine and ${ }^{b}$ Surgery, Johns Hopkins University School of Medicine, Baltimore, Md., USA
}

\section{Key Words}

Acute kidney injury · Ischemia/reperfusion · Acute lung injury $\cdot$ Apoptosis

\begin{abstract}
Despite advances in renal replacement therapy, the mortality of acute kidney injury (AKI) has remained high, especially when associated with distant organ dysfunction such as acute lung injury (ALI). Mortality rates for combined AKI/ALI reach $80 \%$ in critically ill patients. While the clinical presentation of AKI-associated ALI is characterized by increased pulmonary edema, a defining feature of the syndrome, the AKI-induced lung effects extend beyond simple volume overload. Furthermore, ALI and associated mechanical ventilation frequently lead to a decline in renal hemodynamics, structure and function. New experimental data have emerged in recent years focusing on the interactive effects of kidney and lung dysfunction, and these studies have highlighted the pathophysiological importance of proinflammatory and proapoptotic pathways as well as the complex nature of interorgan crosstalk. This review will examine our current understanding of the deleterious kidney-lung crosstalk in the critically ill.

Copyright $\odot 2009$ S. Karger AG, Basel
\end{abstract}

\section{Epidemiology}

Acute kidney injury (AKI) remains one of the most complex clinical problems in modern medicine. AKI occurs in up to $30 \%$ of critically ill patients and a recent multicenter, multinational study reported that $5-6 \%$ of the patients in intensive care units suffered from AKI and required renal replacement therapy (i.e. dialysis) [1,2]. Despite improvements in dialysis technology and advances in supportive care, the morbidity and mortality associated with AKI has remained unchanged over the past 2 decades [3, 4]. In fact, a recent cross-sectional study of 19,982 hospitalized patients found that even a modest rise in serum creatinine $(\geq 0.5 \mathrm{mg} / \mathrm{dl})$ was associated with a 6.5 -fold increase in the odds of death [5]. AKI rarely occurs in isolation and it has become apparent that much of the increased risk of death is actually derived from extrarenal complications, usually related to distant organ dysfunction.

In particular, kidney failure can adversely affect the lungs. This observation dates back to the 1950s when it was identified that patients suffering from AKI manifested abnormal chest X-rays thought to be secondary to 'increased permeability of congested pulmonary capillaries' [6]. These lung changes were identified as pathognomonic for chronic kidney disease and dubbed 'uremic lung'. With the introduction of dialysis, many believed that uremic lung was no longer a real entity. The lung chang-

Heitham T. Hassoun, MD

Johns Hopkins University School of Medicine

720 Rutland Avenue, Ross 749

Baltimore, MD 21205 (USA)

Tel. +1 443287 2312, E-Mail hhassou1@jhmi.edu 
Fig. 1. Kidney-lung interactions during acute injury. AKI induces distant organ effects on the lung via cellular and soluble mediators. ALI, in turn, facilitates and exacerbates kidney dysfunction via metabolic and biomechanical derangements [74, adapted from fig. 2].

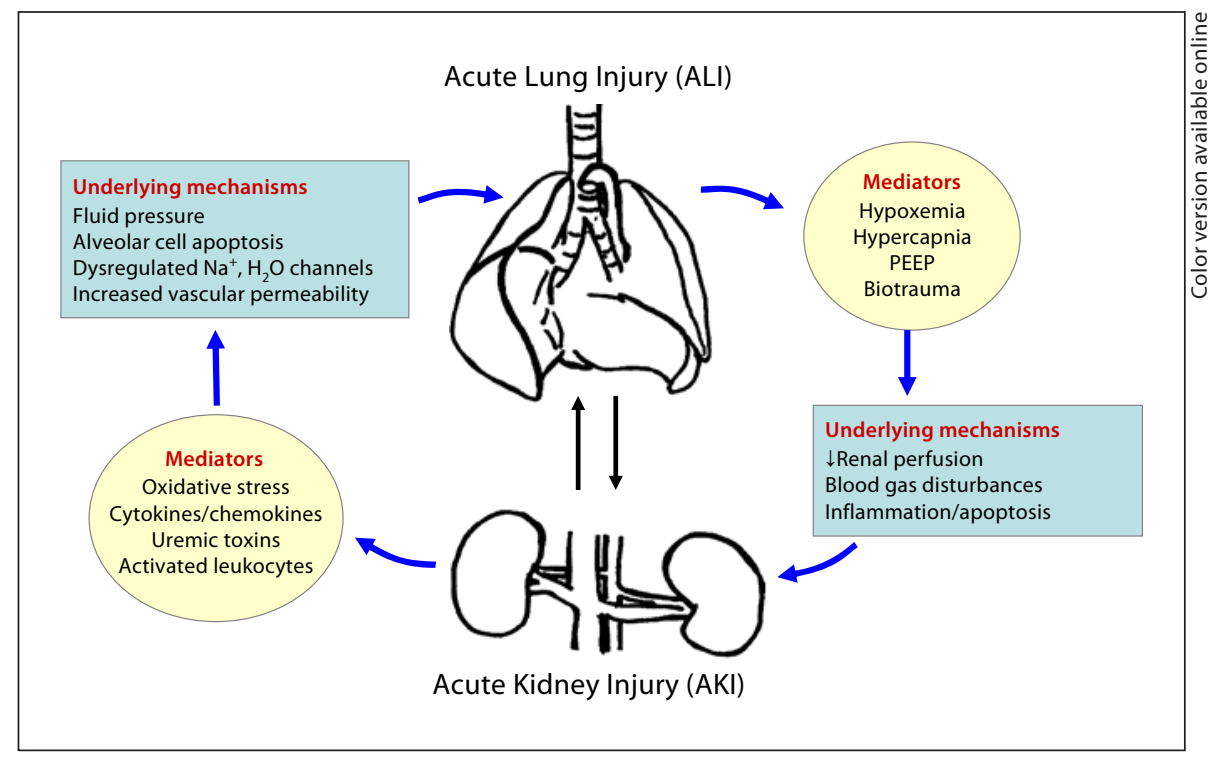

es observed during kidney dysfunction were entirely due to increased effective blood volume and dialysis was the sole answer for patients with AKI. Unfortunately, over the last 50 years there has been limited improvement in the high mortality rate associated with AKI despite improvements in dialysis technology and advances in supportive care. The association of acute lung injury (ALI) with AKI is particularly common in critically ill patients, and mortality exceeds $80 \%$ when they are combined [7].

This profound increase in mortality attributable to combined lung and kidney failure reflects, in large part, the severity of underlying illness in patients with multiple organ failure. For instance, AKI has been associated with more difficult weaning from mechanical ventilation and prolonged intensive care unit stays. A recent analysis of data from the acute respiratory distress syndrome (ARDS) network revealed that the development of AKI (defined as a rise in serum creatinine of $>50 \%$ from baseline over the first 4 study days) in patients with ALI resulted in a mortality rate of $58 \%$ compared to a mortality of $28 \%$ in those ALI patients who did not develop AKI $[8,9]$. Furthermore, ALI with its attendant hypoxemia, hypercapnia and mechanical ventilation-associated high positiveend expiratory pressure (PEEP) worsened renal hemodynamics and function [10]. An increasing body of evidence suggests that these deleterious kidney-lung interactions or 'crosstalk' could, at least in part, be due to a loss of the normal balance of immune, inflammatory and soluble mediators that occurs during severe insults such as shock, trauma, sepsis, etc. (fig. 1). Kidney-lung crosstalk in the critically ill therefore constitutes not only a pressing clinical problem, but also an illuminating framework in which to consider possible mechanisms of multiple organ failure and how the kidney can play a central role in this deadly syndrome.

\section{Pathophysiology}

\section{Acute Lung Injury}

ALI and its most severe manifestation, ARDS, are major causes of morbidity and mortality in critically ill patients. Clinically, the extent of ALI/ARDS is classified according to the requirement of fractional inspired oxygen. If cardiac filling pressures are not elevated, $\mathrm{a} \mathrm{PaO}_{2} / \mathrm{FiO}_{2}$ less than 300 meets criteria for ALI, and a value less than 200 is defined as ARDS [11]. ALI is essentially a noncardiogenic pulmonary edema that occurs in the context of increased alveolar fluid secondary to an increase in lung endothelial or epithelial permeability and/or a decrease in the efficiency of clearance of interstitial fluid.

Structurally, the respiratory bronchioles and alveoli are in direct apposition to the lung interstitium through which the pulmonary capillaries course. Once transvascular fluid has collected in the interstitium, fluid is then drained by pulmonary lymphatics. The tight alveolar epithelial barrier is critical in preventing alveolar flooding by interstitial edema fluid. Therefore, alveolar flooding varies not only with the microvascular endothelial permeability, but also with the capacity for pulmonary lym- 
Fig. 2. Biological processes activated in the lung following kidney ischemia. Gene ontology analysis of ischemia-specific lung genes identified early activation $(Z>2.0)$ of genes related to the innate immune response and cell adhesion bioprocesses, and later activation of genes related to response to stress and cell motility. Genes related to apoptosis and inflammation bioprocesses were activated across time points during ischemic AKI.

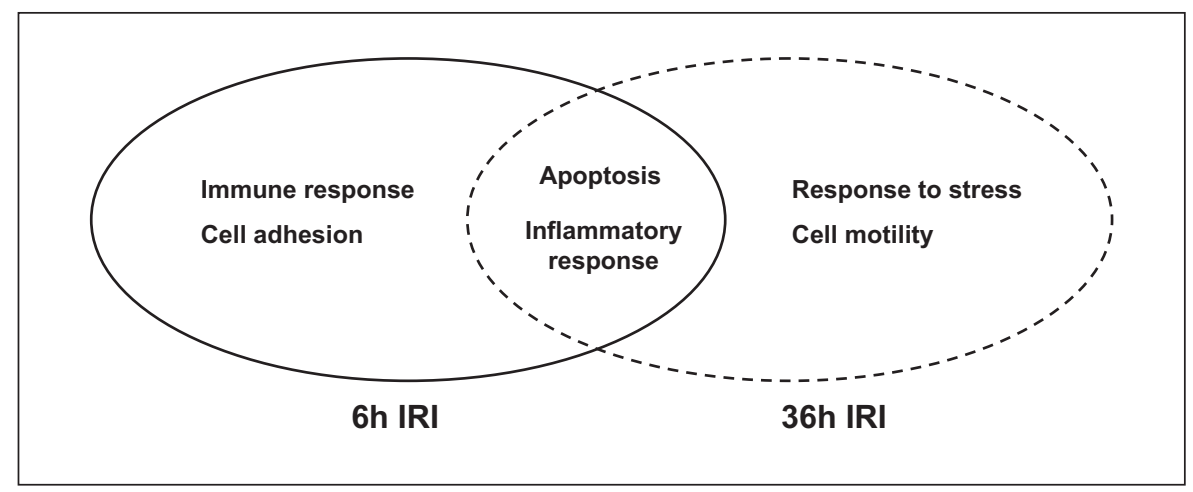

phatic drainage of interstitial fluid and with the integrity of the alveolar epithelial cell-to-cell junctions. Furthermore, alveolar fluid is removed from the distal air spaces by active sodium and chloride transport across the alveolar epithelium. Both the type I and type II pneumocytes express apical sodium channels and basolateral sodiumpotassium ATPases that actively pump sodium into the interstitium $[12,13]$. To achieve equilibrium, water is then passively drawn down the resultant osmotic gradient through aquaporin channels. Alterations in either the sodium or aquaporin channels can have profound effects on alveolar fluid balance [14-16].

The primary molecular and cellular mechanisms of ALI are incompletely understood and are likely to be multifactorial, including oxidative stress, activation of the innate immune response, inflammation, coagulation and apoptosis. In addition, the likely determinants of the complex and coordinated response to insult include cytokines/chemokines, leukocytes, and platelet activation resulting in endothelial and epithelial injury as well as increased capillary and epithelial permeability [6]. Increased permeability leads to a flux of proteins and solutes that increase oncotic pressure favoring alveolar flooding. This leads to impaired alveolar fluid clearance mediated by the aforementioned mechanisms including apoptosis and necrosis of the alveolar epithelium and/or by injury to the apical or basolateral transporters by cytokines, oxygen radicals, etc. $[6,12,17]$.

\section{Effects of AKI on the Lung}

As evidenced in the recent multicenter ARDS Network trial, ALI is exacerbated by an increase in capillary hydrostatic pressure (i.e. heart failure or volume overload), a condition that may often occur in the setting of renal failure [18]. However, experimental evidence suggests that pulmonary injury and edema during AKI oc- curs even in the absence of volume overload [19]. Indeed, lung injury in the setting of AKI is characterized by marked pulmonary vascular congestion, interstitial edema, focal alveolar hemorrhage and inflammatory cell infiltration [20, 21]. Kidney ischemic/reperfusion injury (IRI) in rodents leads to an increase in pulmonary vascular permeability, as evidenced by extravasation of Evans blue dye into the lung parenchyma, an increased lung wet/dry ratio and/or an increase in the bronchoalveolar lavage protein concentration [20-22]. These lung effects of AKI are not limited to the endothelium; kidney IRI also leads to down-regulation of the epithelial salt and water transporters ENaC, Na, K-ATPase and aquaporin5 in the rat lung, which all contribute to decreased alveolar fluid clearance [19].

The type of kidney insult may also impact the presence, timing and severity of distant organ effects of AKI. For instance, the effects of kidney IRI on the lung's salt and water transporters were also observed in bilateral nephrectomized rats, suggesting that uremia rather than reperfusion products were primarily responsible for these observations. The primary importance of uremia in the AKI-induced distant organ lung effects have been corroborated by 2 other rodent studies that have documented lung injury and inflammation following bilateral nephrectomy $[23,24]$. However, a subsequent study by our group comparing established murine models of ischemic AKI and bilateral nephrectomy found structural and functional (i.e. microvascular permeability) changes in the lung following IRI, but not bilateral nephrectomy, when compared to sham controls. In addition, global gene expression profiling of lung tissues identified ischemia-specific changes in the lung transcriptome which were distinguishable from those produced by uremia alone [21] and involved early and persistant activation of proinflammatory and proapoptotic pathways (fig. 2). 
ALI also occurs following IRI of other visceral organs such as the liver and intestine, and it is likely that kidney IRI-induced distant organ effects are related to both uremia as well as reperfusion products. In fact, this unique combination may distinguish the ischemic AKI phenotype from other reperfusion injuries $[25,26]$.

\section{Mechanisms of AKI-Associated Lung Injury}

Role of Inflammation and the Innate Immune

Response

Inflammation is a major component of the initiation and exacerbation of AKI. Given that mediators of systemic inflammation are typically activated during AKI and coupled with decreased kidney clearance, inflammation and the innate immune response are likely important mechanisms connecting the effects of AKI on the lung [27-29]. A recent comprehensive genomic map and analysis of inflammation-associated transcriptional changes in local and remote organs during ischemic AKI identified markedly similar transcriptomic changes occurring concomitantly in both the kidney and lung during AKI, including significant changes in the expression of 109 prominent proinflammatory genes including Cd14, serum amyloid A 3, lipocalin 2, CXCL-2 and the IL-1 receptor (IL-1r2) [30]. Interestingly, the degree of gene transcription fold changes correlated with the severity of the kidney ischemia/reperfusion injury. For instance, the generated normalized enrichment scores, which reflect the correlation of inflammatory gene set with the transcriptional changes induced by AKI, demonstrated the highest impact for 60-min ischemia in kidney tissues for both early (6 h) and later (36 h) time points, while 30-min kidney ischemia failed to illicit a significant transcriptional response in the lung following kidney IRI.

Cytokines/chemokines play a major role in the initiation and progression of both AKI and ALI, and appear to be prime targets connecting the local and systemic effects of kidney IRI [31]. For instance, after measuring an array of cytokines and chemokines in the kidney and blood of a mouse AKI model, the chemokine KC was found to be up-regulated in the urine, serum and kidney within 1-3 $\mathrm{h}$ of injury [32]. These studies were extended to humans, where Gro- $\alpha$ (a human KC analogue) was significantly increased in the urine of ischemic human kidney transplant recipients. Interestingly, Gro- $\alpha$ levels in urine correlated with graft function and predicted the need for dialysis. In a rat model of kidney IRI, serum IL-1 and TNF- $\alpha$ levels were elevated as early as $1 \mathrm{~h}$ of reperfusion and correlated with the progression of distant organ car- diac injury and apoptosis [33]. A more recent study demonstrated that the acute absence of kidney function in mice, after either ischemic AKI or bilateral nephrectomy, is associated with an increase in multiple serum cytokines/chemokines, including IL- 6 , IL- $1 \beta$ and macrophage inflammatory protein 2 . Although the profiles were unique in each model, lung injury and leukocyte infiltration occurred in both models [23]. Administration of the anti-inflammatory cytokine IL-10 reduced markers of lung injury and inflammation. A subsequent study by the same group in IL- 6 knockout mice has highlighted the critical role of IL- 6 in these distant organ effects of AKI [34].

\section{Oxidative Stress}

Induction of oxidative stress, and its systemic consequences, likely also plays a major role in AKI-induced distant organ lung effects. For instance, in a rat model of rhabdomyolysis-induced oxidative stress, AKI was associated with increased permeability and inflammatory cell infiltration in the lung, and was accompanied by oxidative stress in the lung characterized by an increase in lipid peroxidation and F2-isoprostane as well as a decrease of antioxidant capacity such as reduced glutathione [35]. In addition, unilateral kidney IRI in both mice and rabbits has been shown to decrease distant organ hepatic levels of superoxide dismutase, catalase and glutathione, suggesting that ischemic AKI might compromise the host response to systemic oxidative stress [36, 37].

AKI-induced derangements in the key oxidative stress enzymes, nitric oxide (NO) synthase and heme oxygenase (HO), may also facilitate distant organ lung dysfunction. Disordered NO metabolism in the setting of renal failure is well established. While the cause of this dysregulation is not entirely clear, asymmetric dimethyarginine is felt to play a significant role $[38,39]$. Asymmetric dimethyarginine is an inhibitor of endothelial NO synthase and shifts NO metabolism toward production of oxygen-based free radicals [40]. HO-1, an enzyme that catalyzes the degradation of heme, is responsive to ischemic, nephrotoxic and inflammatory stimuli. Its activation decreases oxidative stress and generates anti-inflammatory and antioxidant metabolites such as carbon monoxide and bilirubin [41]. Mice that are homozygous knockouts for HO-1 are more sensitive to kidney IRI, with subsequent increased kidney injury and inflammation, systemic and remote organ IL- 6 , and increased mortality compared to wild-type controls [42]. Taken together, these studies suggest that oxidative stress is an important component of the distant organ effects of AKI. 


\section{Apoptosis}

There is increasing evidence that pulmonary cell apoptosis may play an important role in the pathophysiology of ALI [43]. Apoptosis is a highly regulated mechanism of cell death in which unwanted, infected or damaged cells are eliminated by the activation of specific deathsignaling pathways. However, untimely or excessive cellular apoptosis has been implicated in a variety of human diseases. Both enhanced pulmonary endothelial/epithelial cell apoptosis and delayed inflammatory cell apoptosis have been associated with ALI [44-46]. Detailed investigations of vascular permeability have underscored the importance of the balance between complex tethering forces involved in cell-to-cell and cell-to-extracellular matrix interactions. These studies have also shown that endothelial apoptosis leads to the disruption of these complex interactions and a potential for loss of endothelial barrier function [47].

While it seems intuitive that increased pulmonary endothelial apoptosis would contribute to the derangements in microvascular permeability (the hallmark of ALI), there have been few studies investigating a direct role for pulmonary endothelial apoptosis in the setting of AKI. A detailed genomic analysis of mouse lung tissue during ischemic AKI has indeed identified the activation of a proapoptotic lung transcriptome [21]. A subsequent mechanistic approach to disease targeting has identified that kidney IRI induces caspase-dependent distant lung endothelial apoptosis which mediates subsequent microvascular dysfunction and ALI [48]. Further studies highlighting the AKI-induced imbalances between complex tethering forces involved in endothelial cell-to-cell and cell-to-extracellular matrix interactions and subsequent lung microvascular dysfunction, as well as the specific pathways involved in these pathophysiological interactions, may lead to novel therapeutic targets for the deadly distant organ effects of AKI.

\section{Role of Leukocytes in Kidney-Lung Crosstalk}

Leukocytes play a fundamental role in the development of ALI/ARDS. The lung, with its large capillary network, is capable of sequestering large numbers of inflammatory/immune cells. While this makes sense from an evolutionary standpoint, given the lung's potential exposure to inhaled pathogens, the presence of a large population of activated leukocytes creates the potential for lung damage due to induction of inflammatory responses. In fact, several recent studies have documented lung leukocyte activation and trafficking during experimental AKI. In rat models of both bilateral kidney IRI and bilateral nephrectomy, studies have shown early and sustained lung neutrophil sequestration $[23,24]$. Utilizing a 45-min unilateral renal IRI model in mice, flow cytometric analysis demonstrated neutrophil infiltration in the damaged kidney as well as in several remote organs, including the contralateral kidney, liver and spleen, as early as $60 \mathrm{~min}$ postischemia [49].

While neutrophils are the key mediators in several models of ALI such as pneumonia, sepsis and mesenteric IRI, their importance in AKI-associated lung injury is less clear. For instance, uremic neutrophils have been shown to attenuate ALI [50]. In this study, mice underwent 32 min of bilateral IRI or bilateral nephrectomy, followed by induction of ALI by intratracheal $\mathrm{HCl}$ instillation and mechanical ventilation. In this established model of severe, neutrophil-dependent lung injury, neutrophil-depleted mice were protected from pulmonary histologic injury and oxygenation impairment. Depletion of endogenous neutrophils from uremic mice with subsequent injection of nonuremic neutrophils (or vice versa) was then performed before induction of lung injury. Only mice that had received uremic neutrophils displayed resistance to lung injury, suggesting that neutrophils may, in fact, be protective in the setting of AKI.

Macrophage and lymphocyte infiltration, and/or proliferation, are other potential mediators of the distant organ effects of AKI. Lung microvascular leak occurs in rats following bilateral kidney IRI, attenuated by the macrophage activation inhibitor CNI-1493 [20]. In addition, unilateral kidney ischemia has resulted in increased macrophages in both the contralateral kidney as well as the cardiac interstitium [51]. Recent data also suggest that the inflammatory cascade set in motion by kidney IRI is, in part, mediated by lymphocytes. T cells are important mediators of renal IRI, and recent data provided evidence that this $\mathrm{T}$ cell response to IRI is dependent on the major histocompatibility complex (i.e. mice lacking the $\mathrm{T}$ cell receptor $\alpha \beta$ were protected from renal IRI and had a blunted cytokine response) [52, 53]. Furthermore, our group has recently reported on the infiltration of activated $\mathrm{CD}^{+} \mathrm{CD}^{+}$cytotoxic $\mathrm{T}$ lymphocytes into mouse lungs during kidney IRI and their potential role in mediating lung apoptosis in this setting [54]. Whether the classical antigen-dependent pathway is activated by endogenous 'alloantigens' liberated in IRI, or by some antigen-independent pathway, is an area of ongoing investigation.

\section{Effects of ALI on the Kidney}

Considerable clinical and experimental data support a direct role for $\mathrm{AKI}$ in the initiation and progression of 
ALI. Alternatively, with its attendant hypoxemia, hypercapnia and mechanical ventilation-associated high PEEP, ALI could also worsen renal hemodynamics, structure and function. Mechanical ventilation itself can induce and/or exacerbate ALI and contribute to distant organ kidney effects in the critically ill. In the ARDS Network study comparing low tidal volume (VT) to conventional VT ventilation, protective modes of ventilation not only improved mortality from ARDS, but led to improved kidney function as well. Specifically, patients receiving $6 \mathrm{ml} /$ $\mathrm{kg}$ VT had a lower number of days with renal failure, defined as an increase in serum creatinine $>50 \%$ over baseline, in the first 28 days compared to patients receiving $12 \mathrm{ml} / \mathrm{kg}$ VT [55].

The relative contribution of mechanical ventilation on AKI, compared with the number of other physiologic derangements occurring in the setting of the underlying disease process leading to ALI, can be difficult to ascertain. Animal models of mechanical ventilation and ALI have been used in an effort to elucidate the relative contributions and the potential mechanisms of ALI-induced acute tubular necrosis. Morphologically, prior studies in mechanically ventilated rats have shown a significant increase in Bowman's space, collapse of the glomerular capillaries and perivascular edema in kidneys of ALI animals induced by high VT mechanical ventilation [56]. The influences of mechanical ventilation on kidney function in the setting of ALI generally fall under 3 categories: hemodynamic changes, blood gas disturbances and biotrauma. Regardless of the proposed mechanism, it is clear that (similar to AKI effects on the lung) derangements in the innate immune/inflammatory response, oxidative stress and cellular necrosis/apoptosis are important components of this organ cross-talk in response to injury.

\section{Mechanisms of ALI-Associated Kidney Injury}

Hemodynamic Changes

It is well established that mechanical ventilation alters hemodynamics, and the mechanisms by which mechanical ventilation and associated ALI alter kidney perfusion include a reduction in cardiac output, redistribution of renal blood flow and stimulation of hormonal and sympathetic pathways [57]. Positive-pressure ventilation alters venous return, cardiac preload, pulmonary vascular resistance and cardiac afterload. A decrease in several parameters of renal function, including glomerular filtration rate, renal blood flow (RBF) and free water clearance have been noted during positive pressure ventilation [58]. Furthermore, in an anesthetized canine model, the institution of $10 \mathrm{~cm}$ of PEEP markedly decreased urine flow rate, urinary sodium excretion and creatinine clearance [59]. Some studies have also demonstrated the redistribution of intrarenal blood flow from cortical to juxtamedullary nephrons during PEEP ventilation despite no changes in total renal blood flow, which has been associated with altered kidney function [59, 60]. Neurohormonal alteration by PEEP, such as activation of the sympathetic and renin-angiotensin systems, and suppression of atrial natriuretic peptide release may also induce fluid retention and diminished $\mathrm{RBF}[61,62]$.

\section{Blood Gas Disturbances}

Blood gas changes induced by ALI/ARDS can also adversely affect renal hemodynamics and function. Severe hypoxemia has been demonstrated to reduce RBF by increasing renal vascular resistance related to the activation of vasoactive factors such as angiotensin II, endothelin and a decrease in NO [63-65]. Hypercapnia was found to correlate inversely with RBF mainly by stimulating noradrenaline release and inducing vasoconstriction [66]. In addition, given that both low $\mathrm{PaO}_{2}$ and high $\mathrm{PaCO}_{2}$ induced apoptosis of renal tubular cells in vitro [67], the potential direct effect of blood gas changes on kidney structure and function should be studied further.

\section{Biotrauma}

Emerging data suggest that the biotrauma induced by mechanical ventilation is associated with the release of proinflammatory mediators into the systemic circulation. In a randomized controlled clinical study, higher levels of the cytokines TNF- $\alpha$, IL-1b, IL-6, and IL- 8 were detected in the bronchoalveolar lavage fluid and plasma of patients ventilated at conventional lung volumes compared with those treated with a lung protective strategy [68]. A follow-up analysis showed that the higher VT group had higher rates of renal failure at $72 \mathrm{~h}$, and that the degree of multiorgan failure correlated with IL- 6 levels [69].

A marked genomic stress response in murine kidneys during high VT ventilation was found in 3 different mouse strains [70]. In a rat model of acid-induced lung injury, increased kidney IL-6 levels and associated lung injury occurred with higher VT ventilation [71]. Distant organ kidney epithelial cell apoptosis has been found with an injurious ventilatory strategy in rabbits, and correlated with elevated soluble Fas ligand and elevated serum creatinines in patients with ARDS [72]. Taken together, these data suggest that mechanical ventilation and associated ALI/ARDS can induce a distant organ inflammatory response associated with AKI. Further stud- 
ies will be needed to forge a cause and effect relationship between injurious mechanical ventilation and kidney injury, and it is quite possible that these effects will not be evident with better control of hemodynamics [73].

\section{Conclusions}

Despite advances in renal replacement therapy, the morbidity and mortality of AKI has remained high, especially when associated with distant organ dysfunction such as ALI/ARDS. Because ALI and renal dysfunction frequently coexist in the critical care setting, the effects of failure of either organ are particularly relevant to the function of the other. Experimental evidence presented in this article provides new evidence for important deleterious kidney-lung interactions or crosstalk that rise, at least in part, due to the loss of the normal balance of immune, inflammatory and soluble mediator metabolism that attends severe insults which induce organ injury.

Lung-kidney crosstalk has significant clinical relevance and the current review highlights novel mecha- nisms of multiorgan failure that can lead to new therapeutic strategies. In addition to adequate volume control, elimination of conventional uremic substances by dialysis and lung protective ventilatory management, novel strategies to block the production of and eliminate more efficiently the effector cells and molecules which mediate deleterious crosstalk between the kidney and lung should be studied further. Mechanical ventilation in ALI patients should aim to both maintain $\mathrm{RBF}$ and adequate $\mathrm{O}_{2}$ and $\mathrm{CO}_{2}$ tension with lung protective strategy, as well as reduce inflammatory mediators. Finally, kidney-lung crosstalk in the critically ill constitutes a pressing clinical problem which also serves as an illuminating framework in which to study the mechanisms by which local organ injury and inflammation have systemic consequences.

\section{Acknowledgement}

Supported by NHLBI P50 HL073944, K08 HL089181 and NIDDK R01 DK54770.

\section{References}

1 Star RA: Treatment of acute renal failure. Kidney Int 1998;54:1817-1831.

- 2 Uchino S, Kellum JA, Bellomo R, Doig GS, Morimatsu H, Morgera S, Schetz M, Tan I, Bouman C, Macedo E, Gibney N, Tolwani A, Ronco C: Acute renal failure in critically ill patients: a multinational, multicenter study. JAMA 2005;294:813-818.

- 3 Palevsky PM, Zhang JH, O'Connor TZ, Chertow GM, Crowley ST, Choudhury D, Finkel K, Kellum JA, Paganini E, Schein RM, Smith MW, Swanson KM, Thompson BT, Vijayan A, Watnick S, Star RA, Peduzzi P: Intensity of renal support in critically ill patients with acute kidney injury. $\mathrm{N}$ Engl J Med 2008;359:7-20.

- 4 Metnitz PG, Krenn CG, Steltzer H, Lang T, Ploder J, Lenz K, Le Gall JR, Druml W: Effect of acute renal failure requiring renal replacement therapy on outcome in critically ill patients. Crit Care Med 2002;30:2051-2058.

5 Chertow GM, Burdick E, Honour M, Bonventre JV, Bates DW: Acute kidney injury, mortality, length of stay, and costs in hospitalized patients. J Am Soc Nephrol 2005;16: 3365-3370.

-6 Bass HE, Singer E: Pulmonary changes in uremia. J Am Med Assoc 1950;144:819-823.

-7 Mehta RL, Pascual MT, Gruta CG, Zhuang S, Chertow GM: Refining predictive models in critically ill patients with acute renal failure. J Am Soc Nephrol 2002;13:1350-1357.
-8 Vieira JM Jr, Castro I, Curvello-Neto A, Demarzo S, Caruso P, Pastore L Jr, Imanishe $\mathrm{MH}$, Abdulkader RC, Deheinzelin D: Effect of acute kidney injury on weaning from mechanical ventilation in critically ill patients. Crit Care Med 2007;35:184-191.

-9 Liu KD, Glidden DV, Eisner MD, Parsons PE, Ware LB, Wheeler A, Korpak A, Thompson BT, Chertow GM, Matthay MA: Predictive and pathogenetic value of plasma biomarkers for acute kidney injury in patients with acute lung injury. Crit Care Med 2007;35: 2755-2761.

10 Kuiper JW, Groeneveld AB, Slutsky AS, Plotz FB: Mechanical ventilation and acute renal failure. Crit Care Med 2005;33:1408-1415.

11 Ware LB, Matthay MA: Acute pulmonary edema. N Engl J Med 2005;353:2788-2796.

12 Matthay MA, Folkesson HG, Clerici C: Lung epithelial fluid transport and the resolution of pulmonary edema. Physiol Rev 2002;82: 569-600.

13 Folkesson HG, Matthay MA: Alveolar epithelial ion and fluid transport: recent progress. Am J Respir Cell Mol Biol 2006;35:1019.

14 Mathay MA, Folkesson HG, Verkman AS: Salt and water transport across alveolar and distal airway epithelia in the adult lung. Am J Physiol 1996;270:L487-L503.
15 Dematte JE, Sznajder JI: Mechanisms of pulmonary edema clearance: from basic research to clinical implication. Intensive Care Med 2000;26:477-480.

16 Verkman AS, Matthay MA, Song Y: Aquaporin water channels and lung physiology. Am J Physiol Lung Cell Mol Physiol 2000;278: L867-L879.

17 Matthay MA, Zimmerman GA, Esmon C, Bhattacharya J, Coller B, Doerschuk CM, Floros J, Gimbrone Jr MA, Hoffman E, Hubmayr RD, Leppert M, Matalon S, Munford R, Parsons P, Slutsky AS, Tracey KJ, Ward P, Gail DB, Harabin AL: Future research directions in acute lung injury: summary of a National Heart, Lung, and Blood Institute working group. Am J Resp Crit Care Med 2003;167:1027-1035.

18 The National Heart, Lung, and Blood Institute Acute Respiratory Distress Syndrome (ARDS) Clinical Trials Network Investigators; Wiedemann HP, Wheeler AP, Bernard GR, Thompson BT, Hayden D, de Boisblanc B, Connors AF Jr, Hite RD, Harabin AL: Comparison of two fluid-management strategies in acute lung injury. N Engl J Med 2006; 354:2564-2575

19 Rabb H, Wang Z, Nemoto T, Hotchkiss J, Yokota N, Soleimani M: Acute renal failure leads to dysregulation of lung salt and water channels. Kidney Int 2003;63:600-606. 
-20 Kramer AA, Postler G, Salhab KF, Mendez C, Carey LC, Rabb H: Renal ischemia/reperfusion leads to macrophage-mediated increase in pulmonary vascular permeability. Kidney Int 1999;55:2362-2367.

-21 Hassoun HT, Grigoryev DN, Lie ML, Liu M, Cheadle C, Tuder RM, Rabb H: Ischemic acute kidney injury induces a distant organ functional and genomic response distinguishable from bilateral nephrectomy. Am J Physiol Renal Physiol 2007;293:F30-F40.

$\checkmark 22$ Deng J, Hu X, Yuen PS, Star RA: Alpha-melanocyte-stimulating hormone inhibits lung injury after renal ischemia/reperfusion. Am J Respir Crit Care Med 2004;169:749-756.

-23 Hoke TS, Douglas IS, Klein CL, He Z, Fang W, Thurman JM, Tao Y, Dursun B, Voelkel NF, Edelstein CL, Faubel S: Acute renal failure after bilateral nephrectomy is associated with cytokine-mediated pulmonary injury. J Am Soc Nephrol 2007;18:155-164.

24 Kim DJ, Park SH, Sheen MR, Jeon US, Kim SW, Koh ES, Woo SK: Comparison of experimental lung injury from acute renal failure with injury due to sepsis. Respiration 2006; 73:815-824.

25 Colletti LM, Cortis A, Lukacs N, Kunkel SL, Green M, Strieter RM: Tumor necrosis factor up-regulates intercellular adhesion molecule 1 , which is important in the neutrophil-dependent lung and liver injury associated with hepatic ischemia and reperfusion in the rat. Shock 1998;3:182-191.

-26 Hassoun HT, Kone BC, Mercer DW, Moody FG, Weisbrodt NW, Moore FA: Postinjury multiple organ failure: the role of the gut. Shock 2001; 15:1-10.

-27 Goes N, Urmson J, Ramassar V, Halloran PF: Ischemic acute tubular necrosis induces an extensive local cytokine response: evidence for induction of interferon-gamma, transforming growth factor-beta 1 , granulocytemacrophage colony-stimulating factor, interleukin-2, and interleukin-10. Transplantation 1995;59:565-572.

-28 Lemay S, Rabb H, Postler G, Singh AK: Prominent and sustained up-regulation of gp130-signaling cytokines and the chemokine MIP-2 in murine renal ischemia-reperfusion injury. Transplantation 2000;69:959963.

-29 Mishra J, Dent C, Tarabishi R, Mitsnefes MM, Ma Q, Kelly C, Ruff SM, Zahedi K, Shao M, Bean J, Mori K, Barasch J, Devarajan P: Neutrophil gelatinase-associated lipocalin (NGAL) as a biomarker for acute renal injury after cardiac surgery. Lancet 2005;365:12311238.

-30 Grigoryev DN, Liu M, Hassoun HT, Cheadle $\mathrm{C}$, Barnes KC, Rabb H: The local and systemic inflammatory transcriptome after acute kidney injury. J Am Soc Nephrol 2008; 19:547-558.
Feltes CM, Van Eyk J, Rabb H: Distant-organ changes after acute kidney injury. Nephron Phys 2008;109:80-84.

$\checkmark 32$ Molls RR, Savransky V, Liu M, Bevans S, Mehta T, Tuder RM, King LS, Rabb H: Keratinocyte-derived chemokine is an early biomarker of ischemic acute kidney injury. Am J Physiol Renal Physiol 2006;290:F1187F1193.

33 Kelly KJ: Distant effects of experimental renal ischemia/reperfusion injury. J Am Soc Nephrol 2003;14:1549-1558.

34 Klein CL, Hoke TS, Fang WF, Altmann CJ, Douglas IS, Faubel S: Interleukin-6 mediates lung injury following ischemic acute kidney injury or bilateral nephrectomy. Kidney Int 2008;74:901-909.

35 Rodrigo R, Trujillo S, Bosco C: Biochemical and ultrastructural lung damage induced by rhabdomyolysis in the rat. Exp Biol Med (Maywood) 2006;231:1430-1438.

36 Serteser M, Koken T, Kahraman A, Yilmaz $\mathrm{K}$, Akbulut G, Dilek ON: Changes in hepatic tnf-alpha levels, antioxidant status, and oxidation products after renal ischemia/reperfusion injury in mice. J Surg Res 2002;107: 234-240.

37 Yildirim A, Gumus M, Dalga S, Sahin YN Akcay F: Dehydroepiandrosterone improves hepatic antioxidant systems after renal ischemia-reperfusion injury in rabbits. Ann Clin Lab Sci 2003;33:459-464.

>38 Wever R, Boer P, Hijmering M, Stroes E, Verhaar M, Kastelein J, Versluis K, Lagerwerf F, van Rijn H, Koomans H, Rabelink T: Nitric oxide production is reduced in patients with chronic renal failure. Arterioscler Thromb Vasc Biol 1999;19:1168-1172.

39 Vaziri ND, Ni Z, Oveisi F, Liang K, Pandian $\mathrm{R}$ : Enhanced nitric oxide inactivation and protein nitration by reactive oxygen species in renal insufficiency. Hypertension 2002; 39:135-141.

-40 Druhan LJ, Forbes SP, Pope AJ, Chen CA, Zweier JL, Cardounel AJ: Regulation of eNOS-derived superoxide by endogenous methylarginines. Biochemistry 2008; 47: 7256-7263.

41 Otterbein LE, Zuckerbraun BS, Haga M, Liu F, Song R, Usheva A, Stachulak C, Bodyak N, Smith RN, Csizmadia E, Tyagi S, Akamatsu Y, Flavell RJ, Billiar TR, Tzeng E, Bach FH, Choi AM, Soares MP: Carbon monoxide has anti-inflammatory effects involving the mitogen-activated protein kinase pathway. Nat Med 2000;6:422-428

42 Tracz MJ, Juncos JP, Croatt AJ, Ackerman AW, Grande JP, Knutson KL, Kane GC, Terzic A, Griffin MD, Nath KA: Deficiency of heme oxygenase-1 impairs renal hemodynamics and exaggerates systemic inflammatory responses to renal ischemia. Kidney Int 2007;72:1073-1080.

-43 Fine A, Janssen-Heininger Y, Soultanakis RP, Swisher SG, Uhal BD: Apoptosis in lung pathophysiology. Am J Physiol Lung Cell Mol Physiol 2000;279:L423-L427.
\$4 Rafi AQ, Zeytun A, Bradley MJ, Sponenberg DP, Grayson RL, Nagarketti M, Nagarkatti PS: Evidence for the involvement of Fas ligand and perforin in the induction of vascular leak syndrome. J Immunol 1998;161: 3077-3086.

45 Matute-Bello G, Liles WC, Steinberg KP, Kiener PA, Mongovin S, Chi EY, Jonas M, Martin TR: Soluble Fas ligand induces epithelial cell apoptosis in humans with acute lung injury (ARDS). J Immunol 1999;163: 2217-2225.

46 Matute-Bello G, Liles WC, Radella F, Steinberg KP, Ruzinski JT, Jonas M, Chi EY, Hudson LD, Martin TR: Neutrophil apoptosis in the acute respiratory distress syndrome. Am J Resp Crit Care Med 1997;156:1969-1977.

47 Dudek SM, Garcia JG: Cytoskeletal regulation of pulmonary vascular permeability. J Appl Physiol 2001;91:1487-1500.

48 Hassoun HT, Lie ML, Grigoryev DN, Liu M, Tuder RM, Rabb H: Pulmonary apoptosis mediates distant organ lung dysfunction during experimental ischemic acute kidney injury. Am J Physiol Renal Physiol. In press.

49 Miyazawa S, Watanabe H, Miyaji C, Hotta O, Abo T: Leukocyte accumulation and changes in extra-renal organs during renal ischemia reperfusion in mice. J Lab Clin Med 2002;139:269-278.

50 Zarbock A, Schmolke M, Spieker T, Jurk K, Van Aken H, Singbartl K: Acute uremia but not renal inflammation attenuates aseptic acute lung injury: a critical role for uremic neutrophils. J Am Soc Nephrol 2006;17: 3124-3131.

51 Tokuyama H, Kelly DJ, Zhang Y, Gow RM, Gilbert RE: Macrophage infiltration and cellular proliferation in the non-ischemic kidney and heart following prolonged unilateral renal ischemia. Nephron Physiol 2007;106: 54-62.

52 Burne MJ, Daniels F, Ghandour AE, Mauiyyeddi S, Colvin RB, O’Donnell MP, Rabb H: Identification of the CD4+ T cell as a major pathogenic factor in ischemic acute renal failure. J Clin Invest 2001;108:1283-1290.

53 Savransky V, Molls RR, Burne-Taney M, Chien CC, Racusen L, Rabb H: Role of the T-cell receptor in kidney ischemia-reperfusion injury. Kidney Int 2006;6:233-238.

54 Lie ML, Liu M, Grigoryev DN, Rabb H, Hassoun HT: Cytotoxic T cell mediated distant organ dysfunction during ischemic acute kidney injury. Academic Surgical Congress, Ft Meyers, 2009.

55 Acute Respiratory Distress Syndrome Network: Ventilation with lower tidal volumes as compared with traditional tidal volumes for acute lung injury and the acute respiratory distress syndrome. N Engl J Med 2000; 342:1301-1308. 
-56 Valenza F, Sibilla S, Porro GA, Brambilla A, Tredici S, Nicolini G, Miloso M, Tredici G, Gattinoni L: An improved in vivo rat model for the study of mechanical ventilatory support effects on organs distal to the lung. Crit Care Med 2000;28:3697-3704.

57 Kuiper JW, Groeneveld ABJ, Slutsky AS, Plotz FB: Mechanical ventilation and acute renal failure. Crit Care Med 2005;33:14081415.

-58 Murdaugh HV Jr, Sieker HO, Manfredi F: Effect of altered intrathoracic pressure on renal hemodynamics, electrolyte excretion and water clearance. J Clin Invest 1959;38:834842 .

59 Hall SV, Johnson EE, Hedley-Whyte J: Renal hemodynamics and function with continuous positive-pressure ventilation in dogs. Anesthesiology 1974;41:452-461.

-60 Moore ES, Galvez MB, Paton JB, Fisher DE, Behrman RE: Effects of positive pressure ventilation on intrarenal blood flow in infant primates. Pediatr Res 1974;8:792-796.

-61 Pannu N, Mehta RL: Effect of mechanical ventilation on the kidney. Best Pract Res Clin Anaesthesiol 2004;18:189-203.

-62 Annat G, Viale JP, Bui Xuan B, Hadj Aissa O, Benzoni D, Vincent M, Gharib C, Motin J: Effect of PEEP ventilation on renal function, plasma renin, aldosterone, neurophysins and urinary $\mathrm{ADH}$, and prostaglandins. Anesthesiology 1983;58:136-141.
63 Ballevre L, Thonney M, Guignard JP: Role of nitric oxide in the hypoxemia-induced renal dysfunction of the newborn rabbit. Pediatr Res 1996;39:725-730.

64 Huet F, Semama DS, Gouyon JB, Guignard JP: Protective effect of perindoprilat in the hypoxemia-induced renal dysfunction in the newborn rabbit. Pediatr Res 1999;45:138142 .

65 Semama DS, Thonney M, Guignard JP: Does endothelin-1 mediate the hypoxemia-induced renal dysfunction in newborn rabbits? Biol Neonate 1995;67:216-222.

66 Anand IS, Chandrashekhar Y, Ferrari R, Sarma R, Guleria R, Jindal SK, Wahi PL, PooleWilson PA, Harris P: Pathogenesis of congestive state in chronic obstructive pulmonary disease: studies of body water and sodium, renal function, hemodynamics, and plasma hormones during edema and after recovery. Circulation 1992;86:12-21.

67 Hotter G, Palacios L, Sola A: Low $\mathrm{O}_{2}$ and high $\mathrm{CO}_{2}$ in LLC-PK1 cells culture mimics renal ischemia-induced apoptosis. Lab Invest 2004;84:213-220.

68 Ranieri VM, Suter PM, Tortorella C, De Tullio R, Dayer JM, Brienza A, Bruno F, Slutsky AS: Effect of mechanical ventilation on inflammatory mediators in patients with acute respiratory distress syndrome: a randomized controlled trial. JAMA 1999;282:5461.
69 Ranieri VM, Giunta F, Suter PM, Slutsky AS: Mechanical ventilation as a mediator of multisystem organ failure in acute respiratory distress syndrome. JAMA 2000;284:43-44.

70 Grigoryev DN, Saad S, Moitra J, Garcia JGN, Barnes KC, Rabb H: Genomic basis of acute kidney injury induced by ventilation-induced acute lung injury (abstract). Am Soc Nephrol Meet, 2006.

71 Gurkan OU, O’Donnell C, Brower R, Ruckdeschel E, Becker PM: Differential effects of mechanical ventilatory strategy on lung injury and systemic organ inflammation in mice. Am J Physiol Lung Cell Mol Physiol 2003;285:L710-L718.

72 Imai Y, Parodo J, Kajikawa O, de Perrot M, Fischer S, Edwards V, Cutz E, Liu M, Keshavjee S, Martin TR, Marshall JC, Ranieri VM, Slutsky AS: Injurious mechanical ventilation and end-organ epithelial cell apoptosis and organ dysfunction in an experimental model of acute respiratory distress syndrome. JAMA 2003;289:2104-2112.

73 Hoag JB, Liu M, Easley RB, Britos-Bray MF, Kesari P, Hassoun H, Haas M, Tuder RM, Rabb H, Simon BA: Effects of acid aspiration-induced acute lung injury on kidney function. Am J Physiol Renal Physiol 2008; 294:F900-F908.

74 Rabb H, Chamoun F, Hotchkiss J: Molecular mechanisms underlying combined kidneylung dysfunction during acute renal failure. Contrib Nephrol. Basel, Karger, 2001, vol $132, \mathrm{p} 45$. 